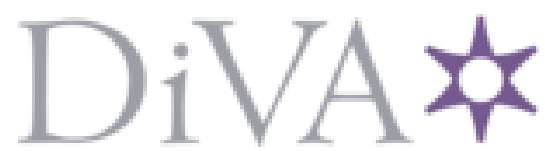

http://www.diva-portal.org

\title{
Preprint
}

This is the submitted version of a paper published in Media Culture and Society.

Citation for the original published paper (version of record):

Stiernstedt, F., Jakobsson, P. (2017)

Watching reality from a distance: Class, genre and reality television.

Media Culture and Society, 39(5): 697-714

https://doi.org/10.1177/0163443716663643

Access to the published version may require subscription.

N.B. When citing this work, cite the original published paper.

Permanent link to this version:

http://urn.kb.se/resolve?urn=urn:nbn:se:sh:diva-31088 


\section{Watching Reality from a Distance: Class, Genre and Reality Television.}

\section{Introduction}

The cultural significance of reality television is based on its claim to represent social reality. On the level of genre, we might argue that reality television constructs a modern day panorama of the social world and its inhabitants and that it thus, in the words of Nick Couldry, 'makes populations appear' (Couldry, 2011). In constructing this supposed window onto social reality, television programmes cannot avoid questions of social class (Wood and Skeggs, 2011). Accordingly, the genre has received a great deal of critical attention for the way it handles social class; that is, how it represents and ritualistically reproduces class divisions (Couldry and Littler, 2011; Ouellette and Hay, 2008). This article presents a class analysis of the population of reality television in which one year of television programming and over 1000 participants have been analysed. The purpose of this analysis is to deepen our understanding of the cultural and ideological dimensions of reality television as a genre, and to give a more detailed picture of the imaginaries of class in this form of television.

Our research questions concern four common claims about reality television. First, we ask whether there is any difference between reality television and other televisual genres in the highlighting or foregrounding of classed identities and classed relationships. Second, we investigate whether reality television is a stage for ordinary people, in the sense that workingclass people populate reality shows to a greater extent than other genres. Third, we ask if reality television gives a voice to working-class participants or if, on the contrary, working-class participants are limited to roles in which they are being talked to, rather than being allowed to speak for themselves. Finally, we address the issue of the relationship between the genre and neoliberal themes of individualization and responsibilisation. 
Some of our findings strengthen previous assumptions about reality television. For example: The reality television genre is more populated by people from the working class than other genres on television are; individualization and responsibilisation are central elements of the genre; and the genre does not give a voice to ordinary people, but on the contrary constitutes an arena where social hierarchy decides on who will have an opportunity to speak. Besides this, the results of this study also revise assumptions from previous studies and bring new knowledge about the reality genre. Most importantly, we show that upper-class people and people belonging to the social elite are over-represented in the genre and appear much more commonly in reality television than in other genres. This result opens up a re-evaluation of the cultural and ideological dimensions of the reality television genre, which we will return to in the final part of the article.

Crucially, however, the contribution of this article is also that it applies a different methodological approach than what has been used so far in order to study the genre of reality television. The quantitative approach taken in this paper gives us new opportunities to speak about the genre as such, without relying on single case studies. This article seek to establish a framework for analysing the genre that has not previously been available. In the conclusion, we discuss in what ways the analytical framework used here can be introduced more broadly within and in relation to the critical and qualitative mainstream work in studies of reality television and in television and cultural studies in general.

\section{Reality and class}

David Morley has noted that "the terminology of class has gradually been deleted from media and cultural studies" (Morley, 2009: 487). The main exception to this, as Morley himself exemplifies, seems to be studies of reality television. It has been claimed that reality television, 
more than other televisual genres, presents classed identities and foregrounds classed relationships (Skeggs and Wood, 2008). In the absence of an actual script or narrative, class relations and class conflict become a shortcut to dramatic development, conflict and closure.

Reality television has furthermore been interpreted as a major site for disseminating neoliberal ideologies of class, consumerism and individualization (Perks, 2007; Skeggs and Wood, 2008). Such ideologies simultaneously hide and reinforce class relations, as narratives of class are reinscribed in terms of self-management and responsibilisation. In relation to this concept, some researchers have analysed reality television as a form of 'governmentality': producing and modelling a certain kind of neoliberal, competitive and individualistic subject. These analyses show how television invites its viewers to act out scripted performances and practise skills and behaviours that are deemed valuable in the neoliberal marketplace (Biressi and Nunn, 2008; McMurria, 2008; Ouellette and Hay, 2008; Windle, 2010). It has been pointed out that the neoliberalism of reality television is highly contextual to American television and that the same forms of neoliberal subjectivisation is not to be found, at least not in the same way, in other television landscapes (Aslama and Pantti, 2007). This is naturally an empirical question and systematic comparative studies, such as the present one, are needed in order to confirm these critical claims.

A more general tendency, reported from various parts of the world, is how reality television is a site for propagating middle-class norms (see for example Kraidy, 2009 for evidence from the Arab World). It has also been observed that reality television portrays working-class people in a negative light (Franco, 2008). This has been most clearly elaborated in relation to so-called makeover formats, in which middle-class people often propagate middle-class norms to working-class people, and sometimes go as far as ridiculing or humiliating them on camera 
(Doyle and Karl, 2008; Meloy, 2009; Ouellette and Hay, 2008; Palmer, 2004; Shugart, 2006; Skeggs, 2009; Tyler, 2008). In many of these shows, there is an implicit denial of the existence of social classes - even as the concept of class underpins the narrative as such - and a dislocation of problems related to social injustices to the realms of psychology and morality (Couldry, 2008; Couldry and Littler, 2011; Skeggs, 2009).

We suggest that reality television performs a mapping of social relations and class relations, which partakes in forming our ability to orient ourselves in society. This claim is line with Couldry's (2011: 203) proposition that reality television is part of 'the continual struggle within modernity to make populations appear, [to] help sustain the plausibility of key assumptions on which modern politics, economies and societies depend'. This work of 'making populations appear', we suggest, is performed on the level of genre: What can be expressed as the ideological efficiency of reality television is predicated on the common traits within the genre that position the interpretive community in such a way as to naturalize notions of class. Genres can be grasped, following Jane Feuer (1992), through an approach that combines aesthetic, ritual and ideological dimensions. A genre is first and foremost a system of aesthetic conventions, which is perceived as such by both the producers and the audiences of texts. However, a genre is also a ritualistic and rule-governed exchange that involves negotiation not only of aesthetics, but also of culturally shared beliefs and values. A genre might then both help to maintain, transform and rejuvenate the social order, as well as work as an instrument of ideological reproduction. If we are to create a reliable cartography of televisual forms, it is thus necessary that we connect the aesthetic conventions of the genre with an in-depth mapping of the social world that is given to us through the programmes of the genre.

\section{Analytical approach and method}


This study uses the method of content analysis, which has long been an established methodology within media studies (Berelson, 1952; Krippendorff, 2013). This method has received criticism for its positivist aspirations and the problems it has in dealing with textual nuances as well as with the impact of the context on the process of interpretation (Thomas, 1994). Inspired by developments in other fields, such as literary studies, we argue that content analysis has a great deal to offer critical and interpretative research in media and cultural studies (Manovich, 2007). A starting point is thus the literary scholar Franco Moretti's work (Moretti, 2013) on what he refers to as 'distant reading' and that we would like to rephrase as 'distant viewing'. In this approach, interpretation and close readings (the preferred methods in previous works on reality television) are bracketed in favour of analysing large sets of empirical material. It is through an analysis of a large quantity of material that we will try to discern the constitutive characteristics of the reality television genre, i.e. the patterns of form and content in relation to the question of class in our sample.

As a matter of course, our analysis will lead to the kind of reductions for which content analysis is usually criticized. Nevertheless, we think that these reductions are necessary in order to understand reality television as a genre. We suggest that the risk of ending up with a reductive understanding of reality television does not lie in the level of the method used, since methods are always trade-offs between paying attention to detail and attempting to view the wider picture. A map that covers the entire territory under study is not only useless, but hides the reality it is supposed to reveal. The danger of reduction lies rather in the tendency for content analyses to be under-theorized and to stop at the question of representation. 


\section{The study}

We explore and analyse the genre of reality television, as expressed in a specific television landscape (Sweden) at a specific moment in time (2015). Most of the materials analysed are, however, not Swedish per se, but consist of imported materials. Only 35\% of the reality programming broadcasted in Sweden is produced in Sweden, and these productions are often adaptations of international formats, with a majority coming from the US. As shown in previous research there might be national and local differences between various adaptions of international formats as well as between different original formats in different countries and regions (Aslama \& Pantti 2007). There has for example been arguments made that the reality genre in the UK differs from its US counterparts since the UK has a large national production of reality shows (Wood \& Skeggs 2011). A general trend however is that the American formats, and format imports, are dominant in many parts of the world. The results presented here is thus arguably transferable and valid for the reality genre in general, in countries residing within the televisual cultural sphere dominated by US programming.

This study includes about 2000 hours of television material, collected from the five largest television channels in Sweden. The study includes the two public service broadcasters in Sweden (SVT1 and SVT2) as well as three commercial broadcasters (TV3, TV4 and Channel 5). Reality television makes up a total of $15 \%$ of the material on these channels, making it one of the largest genres - trumped only by television drama and advertising. The commercial channels broadcast the majority $(87 \%)$ of all reality programming in the sample.

The object of interest in this article is the genre of reality television taken as a whole. Reality television is a complex and multifaceted television genre that incorporates many different subgenres and styles. In the context of this article it is tentatively defined as television programmes 
and formats that claim to represent reality and to be (at least partially) unscripted and to present real people (Fetveit, 1999; Hill, 2005; Holmes and Jermyn, 2004; Wood, 2004). During coding of the material, the coder group also used the industrial classification when coding for genre, accessed through the help of the database IMDb or the homepages of the television channels broadcasting the programme. All the different reality formats included in the sample is listed below:

\section{TABLE 1 HERE}

In total there were 49 different formats in the sample (23 imports, 11 adaptions and 15 original formats). The majority of the original formats were broadcasted at one of the two public service channels There are several different subgenres within the sample. The dominant variant (20) of reality shows in the sample is the documentary style, as for example the different kinds of Real housewifes or occupational reality such as Tunnelbanan [The Subway] or the format Ullared, about a Swedish shopping mall. Social experiments (10) such as Married at first sight are also quite common, competition and game shows (7) and self-improvement (6) are somewhat less common, and even more rare are reality shows about renovation (3) and about economic or financial transactions (3), such as for example Extreme Home Makeover or Million Dollar Listing. The internationally popular format of legal reality (e.g. Judge Judy) is absent from the sample and so are also reality about supernatural or paranormal experiences and shows using hidden cameras.

In our analysis, the analytical units are the persons who appear on television, and the sampling unit is time. Sample images were created by pausing the recording at 10 -min intervals. The benefit of this method is that it cuts across all genres and types of output and gives a 
representative picture of what kind of individuals are most frequently portrayed in the material as a whole. In addition to the persons appearing in each image, each sampling unit was also classified according to more general attributes, such as genre. In total, we collected 12,000 sampling units and 7000 analytical units (since not all sampling units contained people). Of these, 1063 analytical units come from reality television.

We coded the analytical units (i.e. each person appearing in a sample image) in relation to variables such as age, gender, occupation and class, as well as in relation to how they are partaking and how they are portrayed within the programme. All coding have been done with the programme as context, for example when deciding what importance the person has or what occupation s/he holds. The most important variables in the analysis are:

- Class;

- Employment status;

- Occupation;

- Importance in the programme; and

- Mode of occurrence.

We use a definition of the term "class" that acknowledges that a person's formal position in relation to the mode of production is of primary importance in determining class position. Hence we operate with three possible class positions: working-class people who sustain themselves by selling their labour, upper-class people who live off capital and/or off the labour of others, and middle-class people who cover the broad range of functionaries who deal with capital (administrators and clerks, middle managers, etc.) and who also include professionals such as academics, doctors, lawyers and journalists. Although the latter group must also sell their labour power in order to sustain themselves, they have a relative degree of autonomy in 
relation to production. The upper class is here defined in formal, sociological terminology. In the television programmes this group is composed by for example successful entrepreneurs, wealthy business-owners, rentiers, top-tier venture capitalists, large-scale employers and the like. In addition to this Marxist-oriented class scheme, we used a more Weberian class strata that was developed by John H. Goldthorpe (2000), among others. In this scheme, education and social status is given more weight, and the classification is less relational and more hierarchical.

Both of these ways of measuring rely on determining the occupation of the persons appearing on television, and in general there is no difficulty in doing so. Occupational information is often given directly and if not, is generally revealed in other ways, for example through activities undertaken by the person, clothing (e.g., uniforms) or from the general context of the programme. The occupations of $76 \%$ of the persons in the sample were identified. See Figure 1 below for information about the most common occupations among the different class positions in the analysed sample of reality television. It is, however, sometimes possible to code class based on factors other than occupation (e.g., explicit references to capital and resources, or representations of certain kinds of lifestyles). Thus, $80 \%$ of all persons in the material were coded according to class position.

\section{FIGURE 1 IN HERE}

Intercoder agreement is crucial for content analysis. During the research process, several measures were taken to ensure agreement, such as coder training, test coding, joint coding and daily coder meetings with the coder group (made up of five people) to discuss difficult aspects and interesting cases. Several tests for intercoder agreement were also conducted and analysed 
according to Fleiss' Kappa, Cohens' Kappa and Krippendorff's Alpha. Only one of the variables had to be excluded due to weak reliability, while the others gained sufficient reliability according to all three of the measures mentioned above. The average intercoder agreement for all of the variables - according to Krippendorff's Alpha - was 0.770 (H: 939, L: 687).

\section{The visibility of class on reality television}

In the remainder of this article, we will investigate four claims that recur in analyses of reality television. First, we examine whether a difference exists between reality television and other televisual genres in the highlighting or foregrounding of classed identities and classed relationships. Second, we investigate whether reality television is a stage for ordinary people, in the sense that working-class people populate reality shows to a greater extent than other genres. Third, we ask if reality television gives a voice to working-class participants or if, on the contrary, working-class participants are limited to roles in which they are being talked to, rather than being allowed to speak for themselves. Fourth, we address the relationship between the reality television genre and neoliberal themes of individualization and responsibilisation. These claims have been chosen for investigation because they seem to be some of the most interesting, non-trivial claims made about reality television as a genre, while at the same time they have never been confirmed other than in small-scale qualitative case-studies.

The first claim about reality television that we will explore is that a characteristic of the genre is the visibility of classed identities and class conflicts (Tremlett, 2014). Of course, there is no doubt that reality television is on some level about class (since everything in society is). However, the question is to what extent class is a manifest theme within the genre, and whether class is largely used as a narrative driving force and structuring category within the narrative. In order to test these claims for the genre as a whole, we examined three indicators: the visibility 
of class, the interaction between classes and the prevalence of class as a theme. Following this analysis, we cannot find sufficient empirical support to say that reality television is - either in a direct way or on a manifest level - about social class to any greater degree than other genres on television. Naturally, this is not true of all reality programming and probably not for all subgenres of reality television, but the focus of this article is the genre in general.

Visibility. One indication that classed identities are more visible and/or important in a specific genre is that persons appearing on the screen can be coded according to class more frequently than in other genres. From this viewpoint, we perceived no differences between reality television and the total output. In our material, we were unable to code class position for about one-fifth of the people appearing in reality television, which coincides with the equivalent figure for all the genres combined. The two genres that do stand out in this respect are advertising and sport; whereas reality television, news, drama and film had approximately the same percentage of persons whose class identities were obscured to the viewer.

Interaction. If reality television is about class relations to a greater degree than other genres, or if conflicts between classes in general are used to move the narrative forward (Wood and Skeggs, 2011), then it would be reasonable to expect reality television to devote more time to depicting class interaction than other television genres do. However, there is no such evidence in our material. Television in general, as covered by this study, is very class-segregated. The most common televisual images in our study are depictions of one middle-class person (37\% of output), two middle-class persons together (16\%) or one person from the upper class $(8 \%)$. In general, based on the materials in this study, relations between different social classes - that is, persons of different classes visible at the same time in a sample - only occurs in $10 \%$ of the 
entire output, while in reality television this figure is $12 \%$. There is thus no significant difference between reality television and other genres in terms of class relations.

Class as theme. We analysed all the reality formats in our material (49 items) from a thematic viewpoint and classified them according to the importance of class for the format as such. The result shows that most of these formats were not primarily about social class; class was not a dominant theme in most, class-based values and norms were not important in the narratives and class was mainly present as a background phenomenon (Figure 2). Examples of formats that were judged as "to a large extent being about class" include Undercover Boss, three different variants of The Real Housewives and two self-improvement programmes.

\section{FIGURE 2 HERE}

On the whole we found no empirical support for reality television as a genre being more about class than other genres on television. On the contrary, the results show that social class may not have as important a role in this genre as has been assumed in some of the previous research. Of course, there are differences between different formats of reality television and we do not deny that social class and class conflicts are a crucial part of many reality television programmes. Some reality series most certainly construct narrative tensions and dramaturgical conflicts around categories of social class. However, the same can be said for some drama series (e.g., Downton Abbey (2010-2015)) and feature films (e.g., Maid in Manhattan (2002)) as well as for many documentaries, news programmes, et cetera. More work on the different sub-genres of reality, and more comparative work, is needed in order to better understand the relationship between social class and certain reality programmes. 


\section{Reality television: A stage for the ordinary person?}

The next point of investigation is the claim that reality television shows ordinary people and that it is a genre in which the working class is more visible than in other genres. For example, regarding reality television, Nick Couldry (2003: 102) states that 'ordinary people have never been more desired by, or more visible within, the media'. Graeme Turner (2010) points to how reality television creates unique possibilities for ordinary people to become celebrities. Chris Rojek (2001) has in a broader fashion - but with a clear reference to reality television diagnosed contemporary culture as 'organized around mass communications and staged authenticity' with its main 'accessory' being the 'celetoid', a contemporary 'man without qualities' - a hyper-ordinary celebrity. Furthermore, it has been said that ordinary people often equate with working-class people, making reality television a genre in which the working class is more visible than in television in general (Wood and Skeggs, 2011). In reply to this claim, Biressi \& Nunn (2005: 4) acknowledge that the concept of ordinary people is often used as a euphemism for the working class, but argue that the reality television genre has widened television's definition of ordinary people to include white-collar workers, professionals, artists, and more.

In one respect, ordinariness is an ideational and rhetoric concept that has to do with ideas about what counts as ordinary in a given society. Ordinariness is a performance ('doing being ordinary') that can be staged through what is shown and what is said (Biressi and Nunn, 2013; Sacks, 1984). However, ordinariness is clearly also a statistical question. From this perspective, the most ordinary personas are those that represent the typical citizen in terms of measurable facts such as education, occupation, standard of living, ethnicity and so on. Although these two perspectives on ordinariness are intertwined in actuality, they can still be analytically separated 
and both deserve a thorough analysis. Here, we focus on statistical ordinariness and what it indicates about the claim that reality television is an arena for ordinary people, leaving the issue of performances of ordinariness aside for the moment.

Is it true that the working class is more visible in reality television than in other television genres? Yes, it is. We found a significant difference between reality television and television as a whole: In reality television, working-class people appear twice as often as in television in general. Surprisingly, however, the same is true for the upper class. People belonging to that small group of the most wealthy and influential people in society are also visible twice as often in reality television as in television in general. It is consequently the middle class that is less visible in reality television than in other genres. Reality television as a genre thus paints a deeply polarized picture of social reality, which is in a way a more truthful representation of reality than that which is presented in other genres.

Of course, we do not intend to propose that reality television gives a 'realistic' representation of reality. If we compare the populations of people appearing on reality television with actual populations, we find that the historically well-documented under-representation of workingclass people remains in the reality television genre (Butsch, 2003; Greenberg and Atkins, 1980; Smythe, 1954). According to official statistics, the working class in Europe and in the US makes up roughly $40-50 \%$ of the population (Gilbert, 2015). In reality television, $12 \%$ of the participants belong to the working class.

What is more remarkable, however, is the disproportionally large number of people belonging to the upper class among reality-show participants. As much as $20 \%$ of the people on the reality 
shows in our material belong to this category - a finding that needs further explanation, since it contradicts much of what has been said about reality television.

Most of the people belonging to the upper class on reality television are business owners, and only $10 \%$ belong to the power elite through their occupation (e.g., as a CEO or high-level politician). The social elite represented in reality TV is consequently made up of people with access to considerable wealth but with less formal power. This is probably due to the fact that people with formal power and responsibilities do not have the time for and have little to gain from participating in a reality show. For successful entrepreneurs, however, reality television can be used as a leverage to further promote one's business, which in some cases may be more or less equivalent to one's personal brand. If we examine which lines of business the social elite who appear on reality TV are involved in, we find that most of these people are invested in media, culture, service and retailing (> 80\%).

This finding relates to Nick Couldry's (2003: 200) definition of ordinariness, in which he distinguishes between media professionals and 'ordinary' people (see also Turner, 2010). If we include presenters, programme hosts and other representatives of broadcasters in our analysis, we see that these media professionals appear relatively infrequently in reality TV in comparison with all other genres. In the output as a whole, $16 \%$ are media professionals of this kind, whereas in the reality television genre, only $7 \%$ are media professionals. If we look only at the participants in reality television, however - a perspective that is arguably more informative about the genre - we find that they are not at all ordinary (Figure 3). Among the Swedish population, $2.5 \%$ work in the media or cultural sector, but among the participants of reality television, $29 \%$ are employed by, freelancing for or in other ways affiliated with the media and cultural industries. Couldry (2003) and Turner (2010) are thus both right and wrong in asserting 
that reality television is a zone for non-media professionals. While it is true that the genre gives relatively little space to the presenters of the show, it is not true that the participants are ordinary, because a large proportion of the participants work within the media and cultural industries (cf. Curnutt, 2011). That several of the reality TV participants are working, or aspiring to work within in the media and cultural sector, can be explained in a similar way as to why most of the upper class participants have a professional career within media, culture, service and retailing. First, it might be the case that the participants believe that a reality show might be a positive thing to include on the $\mathrm{CV}$, and secondly that the kind of temporary and free-lance employments one finds in the cultural and media industries makes it possible to be flexible enough to have time and freedom to enter the often long productions of reality television.

\section{FIGURE 3 HERE}

\section{Does reality television give a voice to the working class?}

Thus far, we have established that the working class is more visible in reality television than on television in general. The question remains of how this class is represented. It is often claimed that the working class is portrayed in a stereotypical and degrading way in reality television, and that working-class people are deprived of opportunities to define the situation in which they will be depicted, to set the agenda and to express themselves on their own terms (Meloy, 2009; Shugart, 2006; Skeggs, 2009; Tyler, 2008). In contrast, some researchers, such as Biressi \& Nunn (2005: 8), interpret reality television as a platform from which ordinary people can make their voices heard. Theoretically, the discussion of voice is a question of democracy and social justice. Couldry (2010) argues that social organization should foster people's abilities to speak 
and to be heard. The question of whether the reality television genre deprives or enhances working-class people's opportunities for self-representation can thus be posed as asking whether reality television provides the working class with a 'voice'.

One way to operationalize the question of voice is to examine whether working-class people on reality television get the opportunity to speak, or whether they are mainly spoken to. Our results show striking differences between how much people from different social classes get to speak. When working-class people participate on reality television, they are speaking for $30 \%$ of the time and are only visually present the rest of the time. This should be compared with the upper class, who are speaking for $58 \%$ of the time they are present. The middle class is located between these two positions, speaking $39 \%$ of the time they are present.

Another important issue when exploring the voice (or voicelessness) of different groups on television is to investigate who speaks to whom (Figure 4). If we only consider scenes in which there are two or more persons present and in which the persons are identified as belonging to different classes, we get a sense of this aspect of reality television. Our results show three times as many occasions when a member of the social elite speaks to one or more persons belonging to one of the other classes as there are occasions when a working-class person speaks to a person belonging to a different social class. There are also twice as many occasions when middle-class persons speak to people from other classes as there are occasions when working-class people take the verbal initiative. When it comes to the issue of voice, there is thus no question that rather than supplying working-class people with a voice, the reality television genre is suppressing the voice of workers, and thus constitutes yet another arena where social hierarchy decides on who will have an opportunity to speak. 


\section{FIGURE 4 HERE}

\section{Individualization and responsibilisation}

Another recurring claim about reality television is that it is an ideological instrument with the purpose of spreading neoliberal values of individualism and competitiveness (Couldry, 2008). Furthermore, it is claimed that reality television is part of a process called responsibilisation, which can be described as a naturalization of the notion that things such as education, employment and health are individual rather than social or collective responsibilities (Ouellette and Hay, 2008).

When it comes to individualization, it is clear that this value is a key aspect of reality television, although this is of course true for many other television genres as well (and for media in general). Each person in our material was classified as having 'great significance', 'significance' or 'no or small significance' within the context of the programme. Although the differences between genres are small, it is still interesting to note that reality is the genre in which the most persons are coded as having 'great significance' within the programme. Of the persons appearing in reality shows, $65 \%$ have great significance, in comparison with $53 \%$ in all genres. It would be reasonable to expect film and drama to focus at least as much as reality television on single individuals; however, even though both film and drama are above average (54\% and 56\% respectively), they both involve a larger number of people playing secondary or minor roles than the reality television genre does. There are thus good reasons for claiming that reality television does indeed have a slightly different relationship to the individual than other televisual genres do. 
Furthermore, the individual as an individual is more visually and audibly present in reality television than in other genres on television. Images showing only one individual make up 54\% of all reality television programming, and when persons appear individually on the screen in reality television, they are furthermore often talking about themselves as individuals (or about their place in social relations and networks). The confession room camera and the confessional interview are dominant segments of reality television.

One aspect of responsibilisation is that this neoliberal ideology encourages people to take responsibility for their own lives by becoming entrepreneurs. There is a sense in which employment, and especially long-term employment, is associated with a Fordist mode of production. The self-employed person carries the burden of the risks of unemployment, sickness and old age by himself or herself, rather than relying on the various safety nets that come with employment. Seen from this perspective, it becomes possible to operationalize the question of responsibilisation by analysing the occupational status of participants on reality television. Our analysis also shows that self-employment is strongly over-represented within the genre when compared to official statistics as well as to television in general (Figure 5).

\section{FIGURE 5 HERE}

Self-employment is not only more frequent in reality television than in other genres of contemporary television, it is also much more frequent than in society at large, where only $5.2 \%$ of the workforce is self-employed. Another interesting dimension is that people with a precarious position on the labour market, who belong to the so-called 'precariat' (Standing, 
2011), are strongly over-represented in reality television. This finding likely corresponds to the fact that young people more frequently appear in reality television than in other genres. However, it may also point to the fact that precariousness has become common and hence its portrayal is a reflection of the genre's ambition to represent ordinary people. The proportion of people in temporary employment or hired through staffing agencies has been constantly growing in all developed countries since the 1980s, especially among young people, immigrant groups and the working class, and now makes up $19 \%$ of the Swedish workforce, a number comparable to the corresponding value in most European economies.

An unsettled question remains, however: What causes the over-representation of selfemployment in reality television? It could be argued that reality television utilizes selfemployed people because they match the normative ideals of the genre. Alternatively, it is possible that the genre attracts people who are self-employed because the genre resonates with their personal ethos. A third possible explanation is that self-employed people see reality television as a platform from which they can develop and strengthen their personal brand. Whatever the reason may be, the affinity between self-employment and reality television most certainly partakes in maintaining the general discourse on responsibilisation within the programmes of the genre.

\section{The meaning of reality}

To summarize the results from this analysis of the population of the reality television genre, we can say that many of our findings strengthen previous assumptions about reality television. For example: Reality television is more populated by people from the working class than other genres on television; individualization and responsibilisation are central elements of the genre; 
and the genre does not give a voice to ordinary people, but rather constitutes an arena where social hierarchy decides on who will have an opportunity to speak.

However, the results also bring new knowledge about the reality television genre and modify or revise assumptions from previous studies. For example, we have found that a large proportion of the participants in reality television have jobs within the cultural sector, including the media, which means that if we rely on Couldry's definition of ordinary people as non-media professionals, then participants in reality television are not ordinary. We have argued that this may reflect the fact that participation in reality television may be perceived as a way to further a career in the cultural sector, and that young people in precarious jobs turn to reality television in order to improve their standing on the labour market. The large proportion of service workers in reality television highlights the observation that the skill sets required for participation in reality television overlap with the skills required in the service sector, such as sociability, adaptability, good looks and an accessible personality. The seeming usefulness of reality television may explain the popularity of the genre, both among its audience and its participants.

Furthermore, it is clear from our study that the prevalence of upper-class people in reality television has been greatly underplayed in general characterizations of the genre. Our conclusion from this finding is that reality television should not be understood as a 'demotic' genre, in the sense that it provides a platform for ordinary people. As shown in this paper, the dominant pattern is instead that of a genre in which both the lower and upper strata of society are made visible. This new description of the genre can be used to deepen the ideological analysis. As described earlier, reality television is usually understood as a genre that promotes middle-class values, and the participation of working-class people has thus been understood as serving this function. The appearance of the working class in this genre could therefore be 
described as serving as an object of disidentication for the middle-class gaze (Lyle, 2008; Skeggs, 1997: 93). Naturally, the class-composition of reality television varies between different sub-genres. We do not have detailed enough data at this moment to in a systematic way establish such connections. But for example, it would be reasonable to suggest that the sub-genre of reality about self-improvement to a larger extent includes working-class people as it has been shown in previous research to often include shaming and moralising discourses about of working class people and working class culture. This subgenre is however, as shown above, a rather limited part of the genre as a whole, and the genre as a whole is what has been the object of interest in this analysis.

Our results pose the question of what we should make of the participation of the upper class. Should their participation be seen in the same way as that of the working class - as an object of disidentification - or should the participation of the upper class be attributed to its identificatory potential or aspirational characteristics? Although we are unable to answer this question directly based on our study, it is clearly a question that must be tackled if we are to understand the genre of reality television and, one might argue, the medium of television. The middle class is usually identified as the mediating class - the class upon whose values the media industry rests and the class that fulfils the function of mediating society (Bullock et al., 2001). Does reality television spell the end of an era for the mediating middle class, and how should we understand the prevalence of the upper class in these popular narratives? One difference in the handling of the working class versus the upper class by reality television is that whereas the working class, as discussed above, is often subject to situations of judgement and critique by middle-class persons - the 'judgement shot' (Skeggs and Wood, 2012) - this is rarely the case for upper-class persons. This difference does not in itself prove that the upper class is not being subjected to more subtle forms of judgement, or that the middle-class gaze does not take other forms. We 
might argue, for example, that for the upper class, the judgement-by-proxy constructed by the 'judgement shot' is substituted with a form of critique through parody or satire in reality shows, through which the excessive habits of the upper class are made overtly visible.

There is of course a need to be somewhat careful in generalising these results. The sample represents specific a Western version of the reality genre. The formats in general derives from Western Europe or from the United States. The adaptations and local productions have been done by Scandinavian television companies. Previous studies (Nowak and Ross, 1989) has shown that there are national differences in how class is made visible on television. For example Scandinavian television programs, at least historically, have represented more people from the working class than for example American or British television. The differences have however been shown to be small or even marginal (ibid.). In this case it is difficult to clearly assess the degree of specificity in our sample, but it would not be too farfetched to say that the results at least has some generality for the Western televisual culture, in respect to the reality genre. From our material there is however a possibility to do systematic comparisons between televisual content produced in different countries (but broadcasted in Sweden). Furthermore, the study can, due to its systematic design, be replicated in other televisual cultures and systems. More definite knowledge about the generality of these results is hence possible to retain in the future. To conclude, we would like to situate this study in the larger debates on what forms research on the relationship between media and social class should take. Moretti (2005: 4) has called for a 'more rational literary history' through the study of systems of genres rather than individual texts. We have suggested that distant viewing is an appropriate method for discovering the ways in which television makes 'populations appear' (Couldry, 2011) and the ideological interpretation of genre (Feuer, 1992). It seems to us that our understanding of these issues will remain crippled without large-scale quantitative work that takes on entire genres and their 
evolution, both nationally and internationally. We may be criticized as having to a large extent only confirmed the results from other studies through our quantitative analysis. However, the quantitative confirmation of hypotheses generated from interpretative work is an academic labour that must be done, not least in order to clear the ground for new research. It is also clear, however, that we have identified findings through our analysis that have been missed elsewhere, even by the impressive amount of interpretative work that has been dedicated to reality television. Another argument against the kind of quantitative work presented here is that it is very labour intensive and that it is therefore not worth the extra interpretative purchase. If we compare our study with the amount of work that has been carried out on qualitative analyses on reality television to date, this argument clearly does not hold up. A rigorous and systematic study such as the one reported here could save a considerable amount of work for qualitative researchers in discarding certain routes of research and in suggesting more promising avenues. A moment of distant viewing can thus help to relieve researchers from the hazards of prolonged periods of watching television too close to the screen. 


\section{References}

Aslama M and Pantti M (2007). Flagging Finnishness: Reproducing national identity in reality television. Television \& New Media, 8(1): 49-67.

Banet-Weiser S and Portwood-Stacer L (2006) 'I just want to be me again!' Beauty pageants, reality television and post-feminism. Feminist Theory 7(2): 255-272.

Berelson B (1952) Content Analysis in Communication Research. Glencoe, Ill.: Free Press.

Biressi A and Nunn H (2005) Reality TV: Realism and Revelation. New York: Columbia University Press.

Biressi A and Nunn H (2008) Bad citizens: The class politics of lifestyle television. Exposing Lifestyle Television: The Big Reveal: 15-24.

Bullock HE, Fraser Wyche K and Williams WR (2001) Media images of the poor. Journal of Social Issues 57(2): 229-246.

Butsch R (2003) A half century of class and gender in American TV domestic sitcoms. Cercles 8: $16-34$.

Couldry N (2003) Media Rituals: A Critical Approach. London: Routledge.

Couldry N (2008) Reality TV, or The secret theater of neoliberalism. Review of Education, Pedagogy, and Cultural Studies 30(1): 3-13.

Couldry, N (2010) Why voice matters: Culture and politics after neoliberalism. Thousand Oaks, Calif.: SAGE..

Couldry N (2011) Making populations appear. In: Marawan K and Sender K (eds) The Politics of Reality Television: Global Perspectives. London: Routledge, pp. 194-207.

Couldry N and Littler J (2011) Work, power and performance: Analysing the 'reality' game of The Apprentice. Cultural Sociology 5(2): 263-279.

Curnutt, H (2011) Durable participants: A generational approach to reality TV's 'ordinary' labor pool. Media, Culture \& Society 33(7): 1061-1076.

Doyle J and Karl I (2008) Shame on you: Cosmetic surgery and class transformation in 10 Years Younger. Exposing Lifestyle Television: The Big Reveal: 83-99.

Fetveit A (1999) Reality TV in the digital era: A paradox in visual culture? Media, Culture \& Society 21(6): 787-804.

Feuer J (1992) Genre study and television. Channels of Discourse, Reassembled 2: 138-60.

Franco J (2008) Extreme Makeover: The politics of gender, class, and cultural identity. Television \& New Media 9(6): 471-486. 
Gilbert D (2015) The American Class Structure in an Age of Growing Inequality. Thousand Oaks, Calif.: SAGE.

Goldthorpe JH (2000) On Sociology: Numbers, Narratives, and the Integration of Research and Theory. Oxford: Oxford University Press.

Greenberg BS and Atkins C (1980) Life on Television. Norwood, N.J.: Ablex.

Hill A (2005) Reality TV: Audiences and Popular Factual Television. London: Routledge.

Holmes S and Jermyn D (2004) Understanding Reality Television. London: Routledge.

Kraidy M (2009) Reality television and Arab politics: Contention in public life. Cambridge: Cambridge University Press.

Krippendorff K (2013) Content Analysis: An Introduction to its Methodology. Thousand Oaks, Calif. ; SAGE.

Lyle SA (2008) (Mis)recognition and the middle-class/bourgeois gaze: A case study of Wife Swap. Critical Discourse Studies 5(4): 319-330.

Manovich L (2007) Cultural analytics: Analysis and visualization of large cultural data sets. Manovich. net.

McMurria J (2008) Desperate citizens and good Samaritans: Neoliberalism and makeover reality TV. Television \& New Media 9(4): 305-332.

Meloy M (2009) From kid nation to caste nation: Mobility, privilege, and the paradox of class on reality television. The Journal of American Popular Culture 8(1).

Moretti F (2005) Graphs, Maps, Trees: Abstract Models for Literary History. London: Verso.

Moretti F (2013) Distant Reading. London: Verso.

Morley D (2009) Mediated class-ifications: Representations of class and culture in contemporary British television. European Journal of Cultural Studies 12(4): 487-508.

Nowak K and Ross S (1989) Samhällsklasser och sociala skillnader i TV [Class and social difference on TV]. In: Block E (ed) TV som kulturellt system [Television as a cultural system]. Stockholm: Arkivet för ljud och bild, pp. 83-121.

Ouellette L and Hay J (2008) Better Living through Reality TV. Oxford: Blackwell.

Palmer G (2004) 'THE NEW YOU': Class and transformation in lifestyle television. In: Holmes S and Jermyn D (eds) Understanding Reality Television. London: Routledge.

Perks LG (2007) The nouveau reach: Ideologies of class and consumerism in reality-based television. Studies in Language and Capitalism (2): 101-118.

Rojek C (2001) Celebrity. London: Reaktion.

Sacks H (1984) On doing 'being ordinary’. Structures of Social Action: Studies in Conversation Analysis: 413-429. 
Shugart HA (2006) Ruling class: Disciplining class, race, and ethnicity in television reality court shows. The Howard Journal of Communications 17(2): 79-100.

Skeggs B (1997) Formations of Class and Gender: Becoming Respectable. Theory, culture \& society (London), 99-0948605-9, Thousand Oaks, Calif: SAGE.

Skeggs B (2009) The moral economy of person production: The class relations of selfperformance on 'reality' television. The Sociological Review 57(4): 626-644.

Skeggs B and Wood H (2008) Spectacular morality: 'Reality' television, individualisation and the re-making of the working class. In: Hesmondhalgh $\mathrm{D}$ and Toynbee $\mathrm{J}$ (eds) The Media and Social Theory. London: Routledge, pp. 177-193.

Skeggs B and Wood H (2012) Reacting to Reality Television: Performance, Audience and Value. London: Routledge.

Smythe DW (1954) Reality as presented by television. The Public Opinion Quarterly 18(2): 143-156.

Standing G (2011) The Precariat: The New Dangerous Class. London: Bloomsbury Academic.

Thomas S (1994) Artifactual study in the analysis of culture: A defence of content analysis in a postmodern age. Communication Research 21(6): 683-697.

Tremlett A (2014) Demotic or demonic? Race, class and gender in 'Gypsy' reality TV. The Sociological Review 62(2): 316-334.

Turner G (2010) Ordinary People and the Media: The Demotic Turn. Thousand Oaks, Calif SAGE.

Tyler I (2008) 'Chav mum chav scum' Class disgust in contemporary Britain. Feminist Media Studies 8(1): 17-34.

Windle J (2010) 'Anyone can make it, but there can only be one winner': Modelling neoliberal learning and work on reality television. Critical Studies in Education 51(3): 251-263.

Wood B (2004) A world in retreat: The reconfiguration of hybridity in 20th-century New Zealand television. Media, Culture \& Society 26(1): 45-62.

Wood H and Skeggs B (2011) Reality Television and Class. London: BFI. 